\title{
Number of Days from Date of Initial Pathologic Diagnosis to Date of Additional Surgery for New Tumor Event
}

National Cancer Institute

\section{Source}

National Cancer Institute. Number of Days from Date of Initial Pathologic Diagnosis to

Date of Additional Surgery for New Tumor Event. NCI Thesaurus. Code C156857.

The number of days from the date of the initial pathologic diagnosis to the date of additional surgery for new tumor event. 